\title{
Phosphorus Bioavailability and Migration of Hydroxyapatite in Different Sizes as Phosphorus Fertilizer in Camellia Oleifera Seedlings
}

\author{
Minghao Lin, Pengqi Liu, Li Jun, Wenjun Zhou, and Jun Yuan \\ Key Laboratory of Cultivation and Protection for Non-Wood Forest Trees of \\ Ministry of Education and the Key Laboratory of Non-Wood Forest Products of \\ Forestry Ministry, Central South University of Forestry and Technology, \\ Changsha, Hunan, 410004, China
}

Additional index words. available phosphorus, column experiment, nanofertilizer, particle size, red acidic soil

\begin{abstract}
Low mobility and solubility reduce the availability of traditional phosphorus (P) fertilizer in red acidic soil. Hydroxyapatite (HAP), especially nano-hydroxyapatite ( $n$-HAP), may be more efficient than $P$ fertilizer because of its nanoparticle characteristics. Camellia oleifera $(C$. oleifera) is an edible oil tree whose productivity is greatly affected by $P$ fertilizer. During this study, we investigated the migration of different particle sizes of HAP $(20 \mathrm{~nm}, 200 \mathrm{~nm}$, and $80 \mu \mathrm{m})$ and their effects on the seedling growth of $C$. oleifera cultivar Huashuo (HS) cuttings. A column experiment showed that the efflux ratio was negatively correlated with particle size in red acidic soil. The leaching results revealed that the contents of total $P$ and available $P$ in the $20-\mathrm{nm}$ treatment were significantly higher than those in the $200-\mathrm{nm}$ and $80-\mu \mathrm{m}$ treatments in the deep soil (10-15 cm or 15-20 cm), whereas the application of 20-nm n-HAP caused $13.43 \%$ wastage of available $P$. During the container experiments, 200-nm and 20-nm HAP significantly promoted the growth of the seedlings in terms of seedling height, stem diameter, and biomass. The available $P$ contents in the rhizosphere and nonrhizosphere soils were negatively correlated with the HAP particle sizes. In conclusion, the migration of HAP is inversely correlated with particle size, and HAP improves the $P$ bioavailability in red acidic soil. In summary, 200-nm HAP was the best $P$ fertilizer for the seedlings of HS among the three particle sizes. This study offers preliminary results indicating that 200-nm HAP might be a better $P$ fertilizer compared with other two HAP particle sizes for use in future $C$. oleifera orchards.
\end{abstract}

Phosphorus is an essential macronutrient that significantly influences crop growth and productivity (Qu et al., 2020). Emphasis has been placed on the efficient use of $P$ fertilizer for sustainable plant yield and quality (Ryan 2002). Red soils with low $\mathrm{pH}$ cover an extensive area of southern China (He et al., 2011). Furthermore, $\mathrm{P}$ is easily fixed by clay minerals in red acidic soil, resulting in it being barely absorbed by the roots (Yuan et al., 2017), and it has been estimated that one-third to one-half

Received for publication 7 June 2021. Accepted for publication 22 June 2021

Published online 4 August 2021

This study was supported in part by grants from the Provincial Science and Technology Major Project of Hunan, China (2020NK2050), and by the Forestry Science and Technology Innovation Project of Hunan, China (XLK201987).

Y.J., P.L., and M.L. conceived and designed the experiments. M.L., P.L., L.J., and W.Z. performed the experiments and analyzed the data. M.L., Y.J., and P.L. wrote and reviewed the paper. All authors have read and approved the manuscript.

J.Y. is the corresponding author. E-mail: yuanjun@.csuft.edu.cn.

This is an open access article distributed under the CC BY-NC-ND license (https://creativecommons. org/licenses/by-nc-nd/4.0/). of the arable soils in China are P-deficient, especially red acidic soils ( $\mathrm{Li}$ et al., 2020). Hence, serious environmental pollution is caused by increasing applications of $\mathrm{P}$ fertilizer. Greater environmental awareness and the demand for higher $\mathrm{P}$ availability have prompted researchers to focus on the effective utilization of $\mathrm{P}$ fertilizers in agriculture (Jiao et al., 2012). In addition, leaching is regarded as an important means of transporting $\mathrm{P}$ through the soil (Ukwattage et al., 2020).

Camellia oleifera is an important edible oil plant that is widely planted in red acidic soils (Yang et al., 2016). One of the main factors that restricts the growth of $C$. oleifera (He et al., 2011) is P deficiency, and P fertilizer has been reported to have an important role in the yield and quality of $C$. oleifera (Chen et al., 2007). Nanotechnology is an emerging technology that has been proposed to possess the potential to improve fertilizer formulations and augment plant nutrient uptake (Rai et al., 2015; Wang et al., 2016). Nanoparticles are defined as materials that have at least one dimension at the nano-level (Powers et al., 2006). In soil systems, nanomaterials have the capacity to be nanofertilizers. They can improve the yield of crops by increasing nutrient usage efficiency while reducing the costs of production, thereby promoting the sustainable development of agriculture (Saleem and Zaidi, 2020).

Hydroxyapatite (HAP), especially nanohydroxyapatite (n-HAP), is gradually receiving particular attention as a fertilizer (Koutsopoulos 2002; Szameitat et al., 2021). Research has shown that the zeolite $\mathrm{NaP} 1 /$ hydroxyapatite nanocomposite is useful as an inorganic fertilizer and can release nutrient ions for long periods (Watanabe et al., 2013). The positive effects of HAP on soybean plants are related to its longer permanence in soils compared with regular $P$ fertilizer $\left[\mathrm{Ca}\left(\mathrm{H}_{2} \mathrm{PO}_{4}\right)^{2}\right]$ (Liu and Lal, 2014). Furthermore, triple superphosphate $(20 \% \mathrm{P})$ fertilizer performed better than HAP for wheat (Montalvo et al., 2015). To date, the application of HAP as P fertilizers on C. oleifera has not been reported, and its $\mathrm{P}$ bioavailability in $C$. oleifera in red acidic soil is unknown.

During this study, the availability of three different particle sizes $(20 \mathrm{~nm}, 200 \mathrm{~nm}$, and $80 \mu \mathrm{m})$ of HAP as P fertilizers in red soil was examined using container experiments involving cuttings of $C$. oleifera seedlings of the cultivar $\mathrm{HS}$ as indicator plants. Column experiments were also used to explore the migration of different HAP particle sizes. We hypothesized that 1) a small particle size would increase the migration intensity of HAP in red acidic soil, 2) smaller HAP particles would enhance the contents of total $P$ and available $P$ in the red soil because of their faster dissolution, and 3) n-HAP would have a significant positive effect on the growth of C. oleifera seedlings.

\section{Materials and methods}

Characterization of HAP and soil properties. Three HAP sizes (nominal particle sizes of $20 \mathrm{~nm}, 200 \mathrm{~nm}$, and $80 \mu \mathrm{m}$ ) were provided by Nanjing Emperor Nanomaterial, Co., Ltd. in China. The selection of the size of HAP was based on previous research (Montalvo et al.,2015). The HAP morphology was analyzed using a scanning electron microscope (Li et al., 2017).

The red acidic soils used in this study were collected at a depth of $\approx 30 \mathrm{~cm}$ from Wangcheng District, Changsha, China (lat. $28^{\circ} 23^{\prime} 44^{\prime \prime} \mathrm{N}$, long. $112^{\circ} 80^{\prime} 56^{\prime \prime} \mathrm{E}$ ). The samples of red soils were ground manually and air-dried for $48 \mathrm{~h}$. Then, samples were passed through a mesh sieve $(2 \mathrm{~mm})$ for soil property determinations, column experiments, and container experiments. The $\mathrm{pH}$ values of the soils were determined using a $\mathrm{pH}$ electrode (e201-c) with the ratio of solid to liquid being 1:2.5 (Montalvo et al., 2015) and adding deionized water without $\mathrm{CO}_{2}$. The contents of soil organic matter were determined using the potassium dichromate method (Shi et al., 1996). The samples were digested with concentrated $\mathrm{H}_{2} \mathrm{SO}_{4}+\mathrm{H}_{2} \mathrm{O}_{2}$ to determine the total $\mathrm{P}$ and total nitrogen (Jiang et al., 2017), and the soils were extracted with $0.03 \mathrm{~mol} / \mathrm{L}$ $\mathrm{NH}_{4} \mathrm{~F}+0.03 \mathrm{~mol} / \mathrm{L} \mathrm{HCl}$ to determine the available $\mathrm{P}$ (Jin et al., 2018). The P contents (including total $\mathrm{P}$ and available $\mathrm{P}$ ) and total nitrogen were determined using a discrete 
Table 1. Chemical properties of the soil used during this research.

\begin{tabular}{lcccccc}
\hline $\begin{array}{l}\text { Soil } \\
\text { properties pH (water) }\end{array}$ & $\begin{array}{c}\text { Available P } \\
(\mathrm{mg} / \mathrm{kg})\end{array}$ & $\begin{array}{c}\text { Total P } \\
(\mathrm{mg} / \mathrm{kg})\end{array}$ & $\begin{array}{c}\text { Alox } \\
(\mathrm{g} / \mathrm{kg})\end{array}$ & $\begin{array}{c}\text { Feox } \\
(\mathrm{g} / \mathrm{kg})\end{array}$ & $\begin{array}{c}\text { SOM } \\
(\mathrm{g} / \mathrm{kg})\end{array}$ & $\begin{array}{c}\text { Total N } \\
(\mathrm{g} / \mathrm{kg})\end{array}$ \\
\hline
\end{tabular}

\begin{tabular}{llllllll}
\hline Value & $5.32 \pm 0.02$ & $0.15 \pm 0.01$ & $24.17 \pm 0.83$ & $25.79 \pm 0.54$ & $52.40 \pm 0.59$ & $3.24 \pm 0.21$ & $3.13 \pm 0.10$
\end{tabular} $\mathrm{N}=$ nitrogen; $\mathrm{P}=$ phosphorus; $\mathrm{SOM}=$ soil organic matter.

auto analyzer (Smartchem 200; Westco Scientific Instruments, Rome, Italy). The elemental contents of the soil samples were directly measured using an FD-3022 $\gamma$ spectrometer (Masayasu et al., 2000). The soil properties are shown in Table 1.

Column experiment. Three HAP suspensions $(20 \mathrm{~nm}, 200 \mathrm{~nm}, 80 \mu \mathrm{m})$ and a control were prepared with $0.1 \mathrm{~g}$ of HAP powder per $\mathrm{mL}$ of $0.1 \mathrm{M}$ trisodium citrate solution (used to enhance the dispersion of nanoparticles), followed by mild sonication ( $1800 \mathrm{~W}, 3 \mathrm{~min}$ ) (Montalvo et al., 2015).

With a grain size of $0.7 \mathrm{~mm}$ and a uniformity index of 1.25 , quartz sand (purchased from Sinopharm Chemical Reagent Co., Ltd., China) was used as the packing material for the column experiments. Before use, the sand was soaked in $0.01 \mathrm{M} \mathrm{NaOH}$ solution for 24 $\mathrm{h}$, rinsed with deionized water, and soaked again for an additional $24 \mathrm{~h}$ in $0.01 \mathrm{M} \mathrm{HCl}$ solution before being thoroughly rinsed with deionized water. Then, the sand was dried in an oven at $105^{\circ} \mathrm{C}$ and stored for the experiments (Lv et al., 2012).

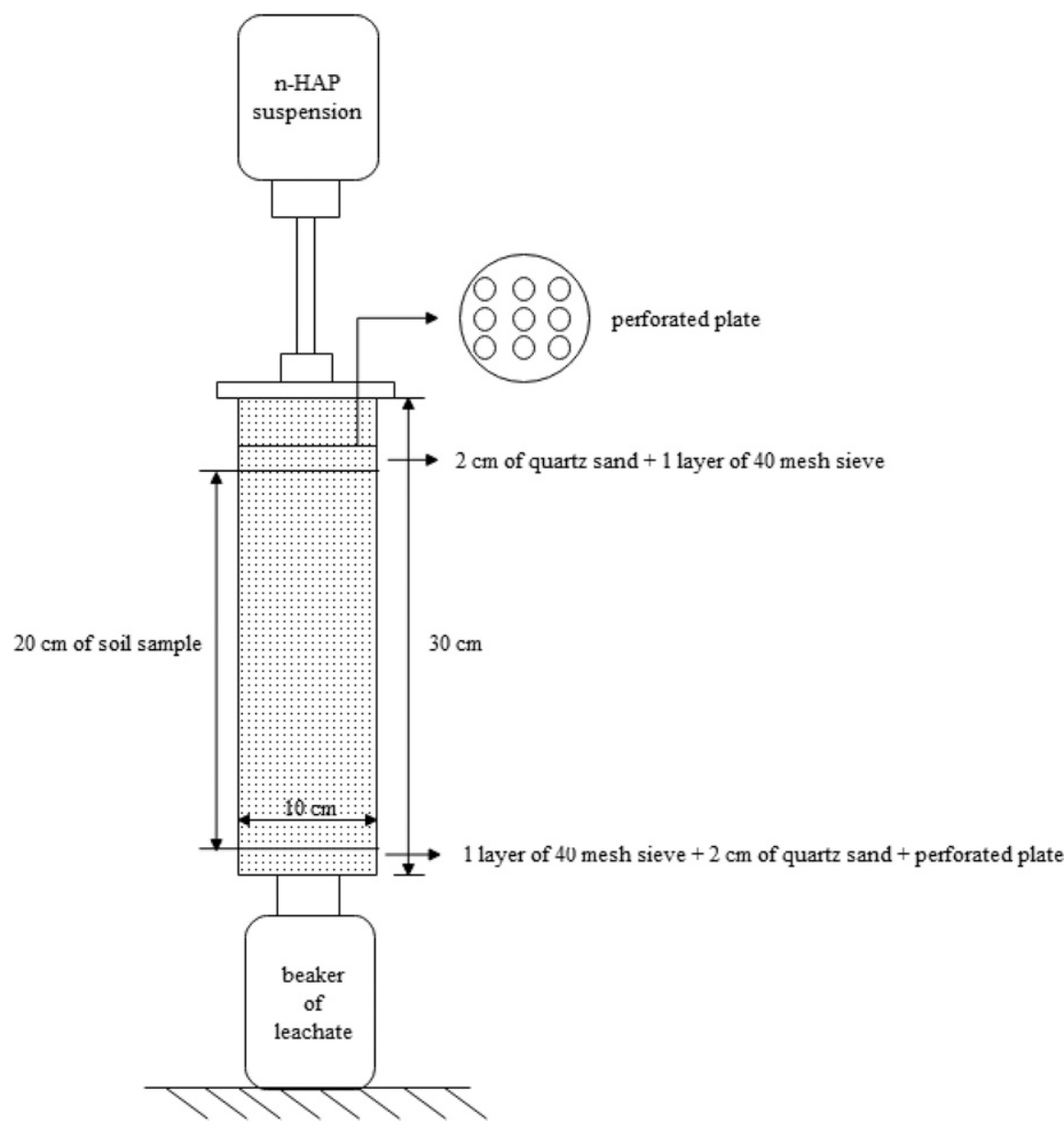

Fig. 1. Diagrammatic sketch of the soil column.
The porosity and pore volume (PV) of the columns were measured gravimetrically (Zhao et al., 2018); then, the columns (inner diameter, $10 \mathrm{~cm}$; height, $30 \mathrm{~cm}$ ) (Fig. 1) were oriented vertically and saturated with deionized water for $48 \mathrm{~h}$ to remove air pockets for subsequent tests (Du et al., 2010).

To prevent the loss of the soil during the experiment, the bottom of the column was covered with 2-cm-thick quartz sand under a $0.425-\mathrm{mm}$ sieve. The air-dried soil samples were packed in the middle of the column. Placement of the quartz sand and sieve at the top of the column was contrary to that at the bottom. The soil columns were leached with 0.5 PV leachate (HAP suspensions) every 3 $\mathrm{h}$, and the leachate was collected in a beaker. The absorbances of the obtained leachates and the initial suspension were measured by an ultraviolet spectrophotometer and recorded as $\mathrm{C}$ and $\mathrm{C}_{0}$, respectively. The breakthrough curves (BTCs) of the HAP were drawn with the pore volume number as the abscissa and $\mathrm{C} / \mathrm{C}_{0}$ as the ordinate. All treatments were replicated six times. 
A

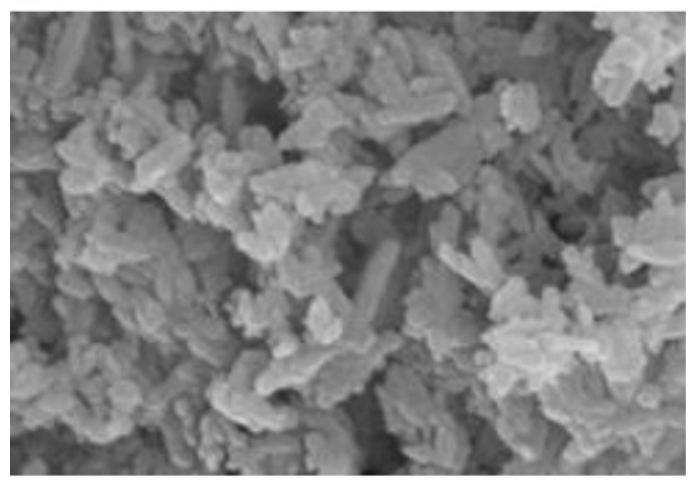

B

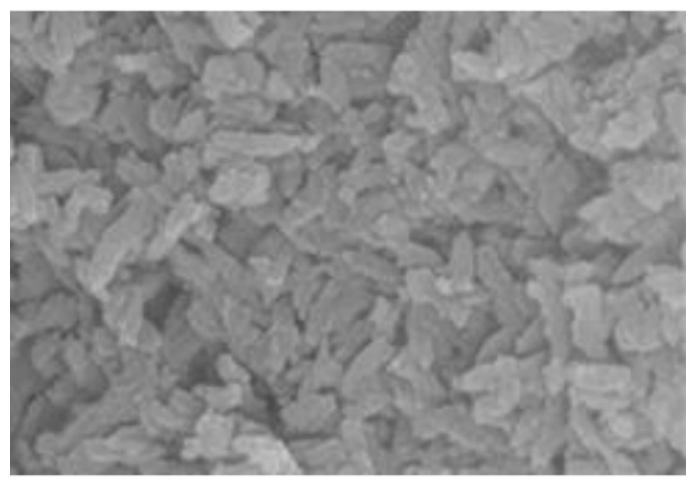

C

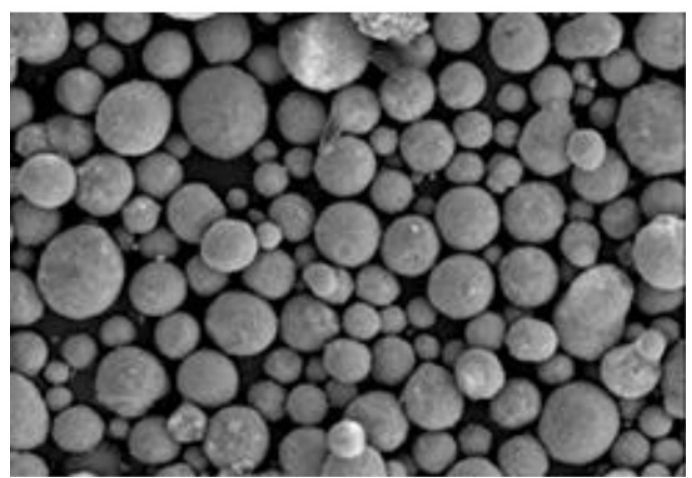

Fig. 2. Scanning electron microscopy images of hydroxyapatite (HAP) of different sizes: (A) $20 \mathrm{~nm}$ nanohydroxyapatite (n-HAP); (B) $200 \mathrm{~nm}$ HAP; and (C) $80 \mu \mathrm{m}$ HAP.

\section{Results}

Characterization of HAP. The scanning electron microscopy results for HAP (Fig. 2) showed that the HAP morphology of the 20$\mathrm{nm}$ and 200-nm HAP was needle-like, whereas that of the $80-\mu \mathrm{m}$ HAP was spherical. The P concentrations of the three HAP sizes were $19.40 \%, 20.01 \%$, and $19.71 \%$, respectively, which are close to the theoretical value of HAP $(18.50 \%)$.

Column experiment. The BTCs of the column experiment (Fig. 3) characterized the change in HAP concentration with relative time $\left(\mathrm{C} / \mathrm{C}_{0}\right)$ during the process of migration, thus reflecting the interaction between HAP and the soils (Zang 2011). Our results showed that the efflux ratios of HAP were negatively correlated with the particle sizes. The maximum $\mathrm{C} / \mathrm{C}_{0}$
$(0-10 \mathrm{~cm})$ increased significantly because of the accumulation of large HAP. The P contents were increased by n-HAP in the deep soil $(10-20 \mathrm{~cm})$, which can be explained by their better migration abilities. The available $\mathrm{P}$ contents of the $80-\mu \mathrm{m}$ and 200-nm HAP treatments in the 0 - to $5-\mathrm{cm}$ soil zone were increased by $26.50 \%$ and $20.93 \%$ compared with the control, respectively; however, this value was only $11.93 \%$ in the $20-\mathrm{nm}$ n-HAP treatment. In the 5- to $10-\mathrm{cm}$ soil column layer, the contents of soil-available P of the $200-\mathrm{nm}$ HAP treatment increased most obviously by $14.21 \%$, whereas increases of $7.77 \%$ and $13.92 \%$ were observed for $80-\mu \mathrm{m}$ HAP and 20-nm HAP, respectively. The available P contents of the $20 \mathrm{~nm}$ treatment in the 10- to 20$\mathrm{cm}$ soil zone increased by $6.93 \%$ and $8.42 \%$, respectively. There was no significant difference between the control and the $80-\mu \mathrm{m}$ treatment in the 10- to $20-\mathrm{cm}$ soil column.

Adsorption of HAP by red acidic soil. As the soil depth increased, the total $\mathrm{P}$ contents in the $200-\mathrm{nm}$ and $80-\mu \mathrm{m}$ treatments were reduced, and a significant difference was observed between the $20-\mathrm{nm}$ and the control groups (Fig. 5). The total $\mathrm{P}$ content in the 0 to 5-cm layer of the $80-\mu \mathrm{m}$ treatment (38.94 $\mathrm{mg} / \mathrm{kg}$ ) was significantly higher than that of the other soil zones. In the $5-$ to $10-\mathrm{cm}$ soil zone, the $\mathrm{P}$ contents of the $200 \mathrm{~nm}$ and 80 $\mu \mathrm{m}$ treatments were $33.29 \mathrm{mg} / \mathrm{kg}$ and 33.16 $\mathrm{mg} / \mathrm{kg}$, respectively, which were significantly higher than that with the 20-nm treatment. However, the total $\mathrm{P}$ contents of the $20-\mathrm{nm}$ treatment in the $10-$ to $15-\mathrm{cm}$ and $15-$ to 20 $\mathrm{cm}$ soil layers were $30.74 \mathrm{mg} / \mathrm{kg}$ and 30.13 $\mathrm{mg} / \mathrm{kg}$, respectively, and remarkably higher than those of the others.

The changing trends of soil-available $\mathrm{P}$ contents were similar to those of total $\mathrm{P}$, and the additions of HAP had significant effects on the available $\mathrm{P}$ contents of the soil (Fig. 6). The highest available $\mathrm{P}$ content of the $80-\mu \mathrm{m}$ treatment was 25.89 -times that of the control, followed by those of the 200-nm and $20-\mathrm{nm}$ treatments, which were 25.00 times and 9.28-times that of the control, respectively. In the 5- to $10-\mathrm{cm}$ soil layer, the available P content of the $200-\mathrm{nm}$ treatment was the highest at $1.92 \mathrm{mg} / \mathrm{kg}$, although no significant difference was observed between those of the $20-\mathrm{nm}$ and $80-\mu \mathrm{m}$ treatments, which were $1.25 \mathrm{mg} / \mathrm{kg}$ and $1.07 \mathrm{mg} / \mathrm{kg}$, respectively. However, the contents of available $\mathrm{P}$ in the $20-\mathrm{nm}$ treatment in the $10-$ to $15-\mathrm{cm}$ and $15-$ to $20-\mathrm{cm}$ soil zones were the highest at $1.25 \mathrm{mg} / \mathrm{kg}$ and $1.11 \mathrm{mg} / \mathrm{kg}$, respectively; however, no significant difference was found between those of the $80-\mu \mathrm{m}$ and the control treatments, which were only $0.14 \mathrm{mg} / \mathrm{kg}$ and $0.18 \mathrm{mg} / \mathrm{kg}$, respectively.

A comparison of the soil columns leached with the HAP suspension with the columns eluted with deionized water indicated the available $\mathrm{P}$ content of the $20-\mathrm{nm}$ treatment was significantly increased by $19.36 \%$ in the deep soil $(10-15 \mathrm{~cm}$ and $15-20 \mathrm{~cm})$, indicating that 20 -nm n-HAP demonstrated better migration ability in the red soil. However, the data also showed that 20-nm n-HAP had 


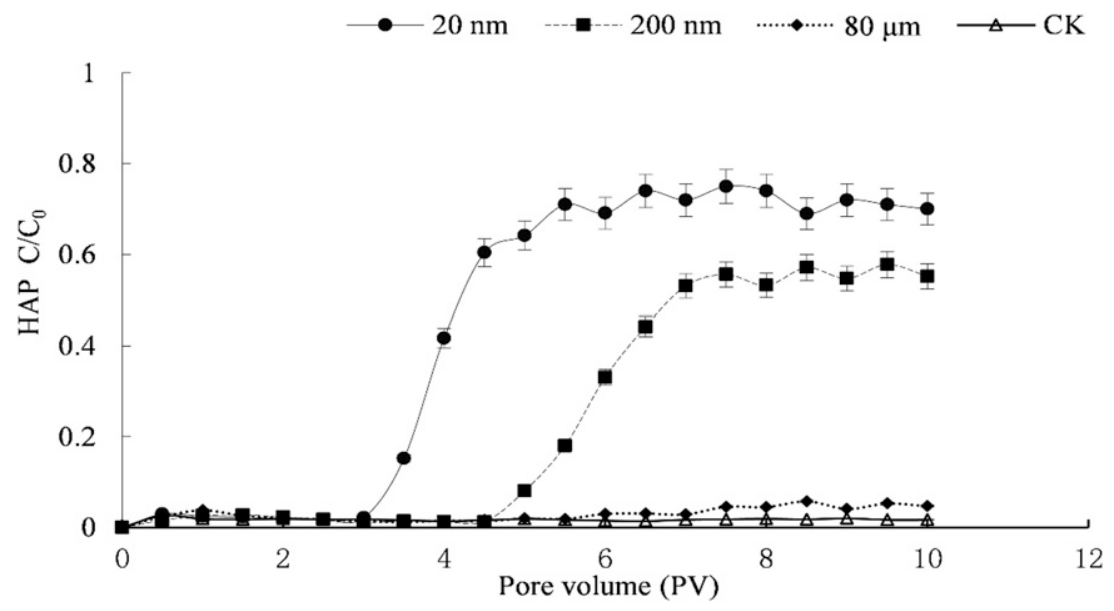

Fig. 3. Effects of different particle sizes on the mobility of hydroxyapatite (HAP) during the soil column experiments.

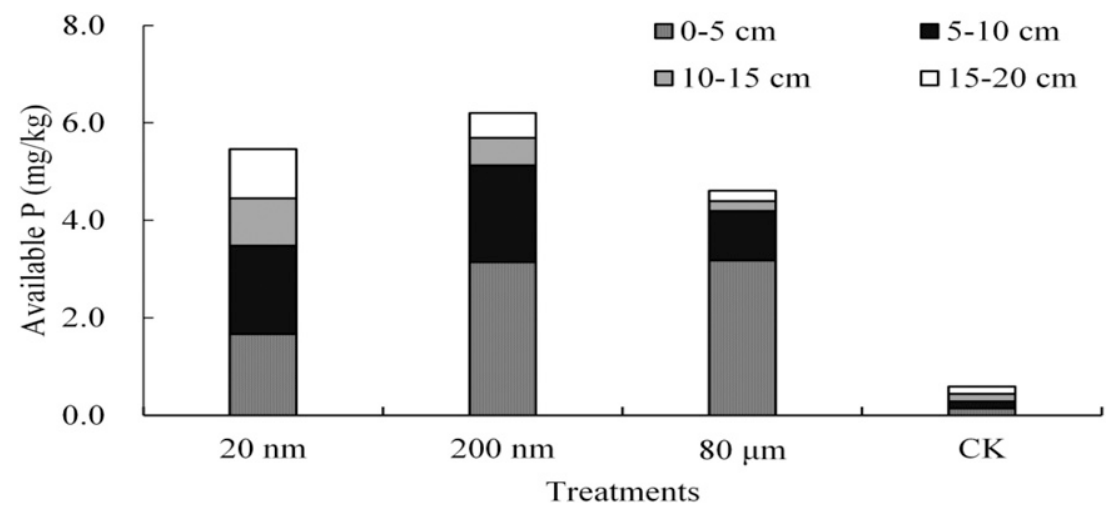

Fig. 4. Effects of different particle sizes of hydroxyapatite (HAP) on the available phosphorus (P) content after leaching in soil columns.

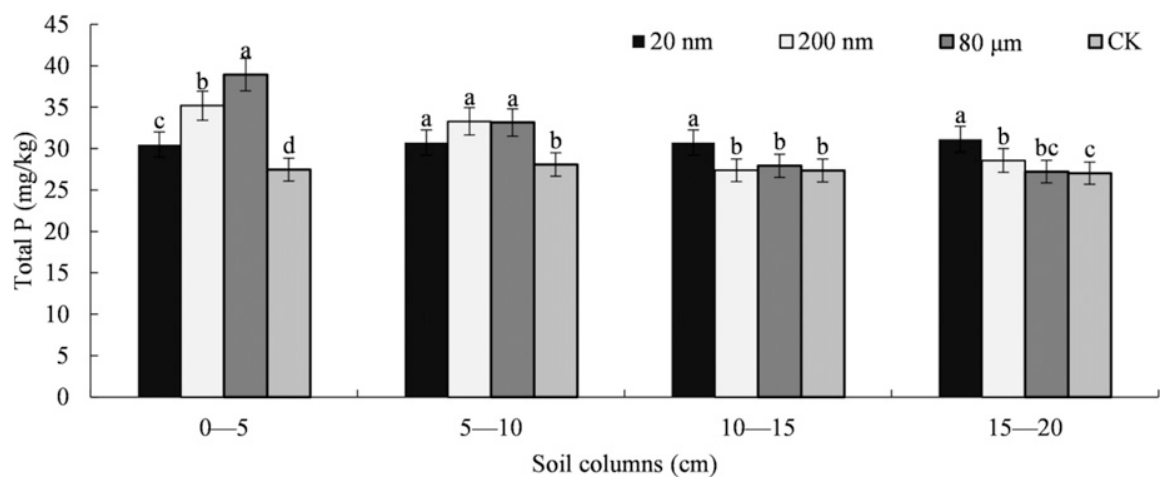

Fig. 5. Changes in the total phosphorus (P) content in the red acidic soil after elution in different treatments. The results are the mean \pm SE of three biological replicates. Different lowercase letters indicate significant differences at a 5\% probability level according to Duncan's multiple range test.

$13.43 \%$ wastage of available $\mathrm{P}$ in the soil after elution, and there were no significant differences between those of the control, 200nm HAP, and $80-\mu \mathrm{m}$ HAP treatments.

Physiological indexes of $\mathrm{C}$. oleifera cultivar HS seedlings. There were significant differences in the physiological indexes of the seedlings treated with different HAP particle sizes (Tab. 2). The height, stem diameter, and biomass of the seedlings were significantly improved by the 200-nm HAP, followed by the $20-\mathrm{nm}$ n-HAP and $80-\mu \mathrm{m}$ HAP. The seedling heights of the $20-\mathrm{nm}$ n-HAP and 200-nm HAP treatments were significantly higher than those of the $80-\mu \mathrm{m}$ HAP treatment and control. The stem diameter of the 200-nm treatment was the highest among all the treatments. The indexes of seedling fresh weight of the 200 -nm treatment were $21.97 \%$ higher than the control. The root-to-shoot ratio of the 200-nm HAP was 0.59 and $1.13 \%$ higher than that of the 20-nm n-HAP.

Effects of different treatments on the $P$ content of the seedlings of $\mathrm{C}$. oleifera cultivar $H S$. The addition of different HAP particle sizes had significant effects on the contents of total $\mathrm{P}$ in the roots, stems, and leaves of the seedlings (Fig. 7), with similar trends observed across the histograms. The total P contents of the seedlings treated with HAP were significantly higher than those of the control. The total $\mathrm{P}$ contents of the $20-\mathrm{nm}$ treatment were the highest, followed by those of the $200-\mathrm{nm}$ and $80-\mu \mathrm{m}$ treatments, whereas no significant differences were found between the $20-\mathrm{nm}$ and 200-nm treatments, except in the leaf.

Available $P$ contents in the rhizosphere and nonrhizosphere soil under different treatments. With the increase in HAP particle size, the available $\mathrm{P}$ contents in the rhizosphere and nonrhizosphere soil was reduced significantly (Fig. 8). The available P contents in the rhizosphere and nonrhizosphere soil of the $20-\mathrm{nm}$ treatment were the highest at $1.79 \mathrm{mg} / \mathrm{kg}$ and $1.13 \mathrm{mg} / \mathrm{kg}$, respectively, followed by those of the 200-nm treatment; the lowest contents were observed in the $80-\mu \mathrm{m}$ treatments, which were only $0.61 \mathrm{mg} / \mathrm{kg}$ and $0.41 \mathrm{mg} / \mathrm{kg}$, respectively. The content of available $\mathrm{P}$ in the 20 -nm treatment in the rhizosphere soil was significantly higher than that of the control. The paired $t$ test showed that there were significant differences among the $20-\mathrm{nm}, 80-\mu \mathrm{m}$, and control treatments; however, there were no significant difference detected between the 20-nm and 200-nm treatments.

\section{Discussion}

Migration of HAP in red acidic soil. The migration of $\mathrm{P}$ in the soil is complex, and $\mathrm{P}$ can travel in different forms (e.g., dissolved, colloidal, and particulate) (Chen and Arai, 2020). Because of the long-term application of $\mathrm{P}$ fertilizer, a large amount of $\mathrm{P}$ has accumulated in the soil; however, the availability of traditional $\mathrm{P}$ fertilizer is limited by its low mobility and solubility (Yuan et al., 2013). Column experiments are a common way of testing the vertical transport of $\mathrm{P}$ in the soil. Our results showed that the mobility of the 20-nm n-HAP was the greatest, followed by that of the 200-nm HAP, whereas the $80-\mu \mathrm{m}$ HAP could hardly penetrate the soil column. This is probably because the large particles of HAP aggregates are easily adsorbed by active sites in the soil or blocked by the tension in the soil pores (Zhang and Wang, 2014). The column experiments indicated that in the 0 to $5-\mathrm{cm}$ soil layer, the retention of $80-\mu \mathrm{m}$ HAP in the soil column led to an increase in the available $\mathrm{P}$ content. However, with the increase in depth, it ultimately did not differ from that of the control. A correlation analysis further confirmed that the adsorbed HAP of different particle sizes in the 0 - to 5-cm column was positively correlated with the total $\mathrm{P}$ content of the soil after elution. We found that the distribution of available P with the 200-nm HAP was similar to that with $80-\mu$ m HAP, but the content with the 200-nm HAP was higher, which was related to its stronger penetration ability. The uniform distribution of available $\mathrm{P}$ in the 20 -nm HAP soil column indicated its better penetration ability in red soil, which was consistent with the results of the BTCs. In addition, it is believed that the 


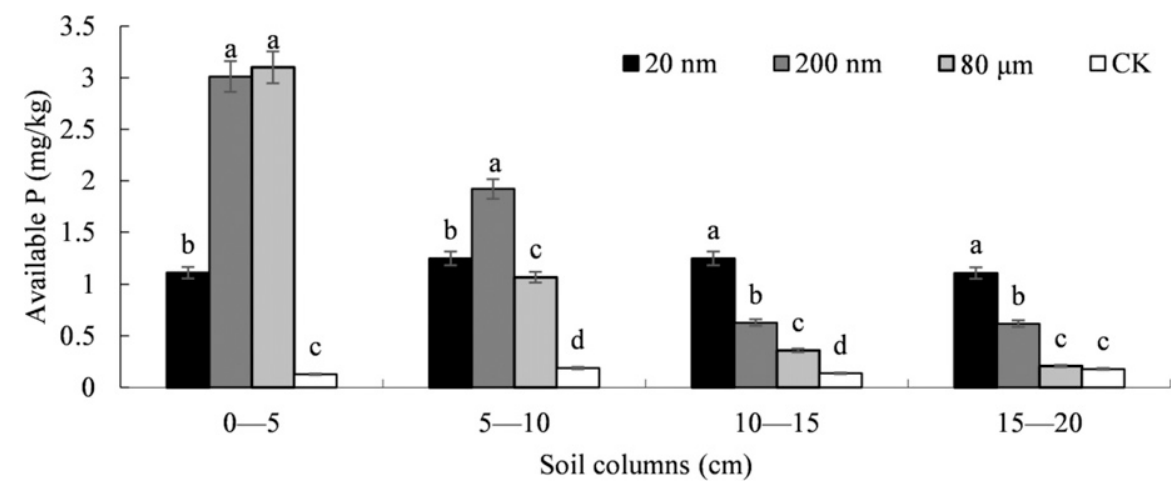

Fig. 6. Changes in available phosphorus $(\mathrm{P})$ contents in red acidic soil after elution in different treatments. Mean values $(n=3)$ followed by different lowercase letters in each column indicate significant differences at $\mathrm{P}<0.05$ according to Duncan's multiple range test.

Table 2. Effects of different treatments on the morphological indexes of the seedlings of C. oleifera cultivar Huashuo.

\begin{tabular}{lccccc}
\hline Treatment & Seedling ht $(\mathrm{cm})$ & $\begin{array}{c}\text { Stem } \\
\text { diam }(\mathrm{mm})\end{array}$ & $\begin{array}{c}\text { Fresh wt of } \\
\text { seedlings }(\mathrm{g})\end{array}$ & $\begin{array}{c}\text { Dry wt of } \\
\text { seedlings }(\mathrm{g})\end{array}$ & $\begin{array}{c}\text { Root-to- } \\
\text { shoot ratio }\end{array}$ \\
\hline $20 \mathrm{~nm}$ & $10.39 \pm 0.26 \mathrm{a}$ & $2.25 \pm 0.11 \mathrm{~b}$ & $4.70 \pm 0.06 \mathrm{a}$ & $1.69 \pm 0.05 \mathrm{~b}$ & $0.52 \pm 0.02 \mathrm{c}$ \\
$200 \mathrm{~nm}$ & $10.33 \pm 0.18 \mathrm{a}$ & $2.48 \pm 0.10 \mathrm{a}$ & $4.83 \pm 0.11 \mathrm{a}$ & $1.97 \pm 0.03 \mathrm{a}$ & $0.59 \pm 0.07 \mathrm{c}$ \\
$80 \mu \mathrm{m}$ & $9.13 \pm 0.06 \mathrm{~b}$ & $2.27 \pm 0.07 \mathrm{~b}$ & $4.19 \pm 0.08 \mathrm{~b}$ & $1.30 \pm 0.07 \mathrm{c}$ & $1.01 \pm 0.03 \mathrm{~b}$ \\
Control & $8.71 \pm 0.09 \mathrm{c}$ & $2.06 \pm 0.06 \mathrm{c}$ & $3.96 \pm 0.08 \mathrm{c}$ & $1.14 \pm 0.04 \mathrm{~d}$ & $1.16 \pm 0.04 \mathrm{a}$ \\
\hline
\end{tabular}

Mean values $(n=3)$ followed by different lowercase letters in each column indicate significant differences at $P<0.05$ according to Duncan's multiple range test.

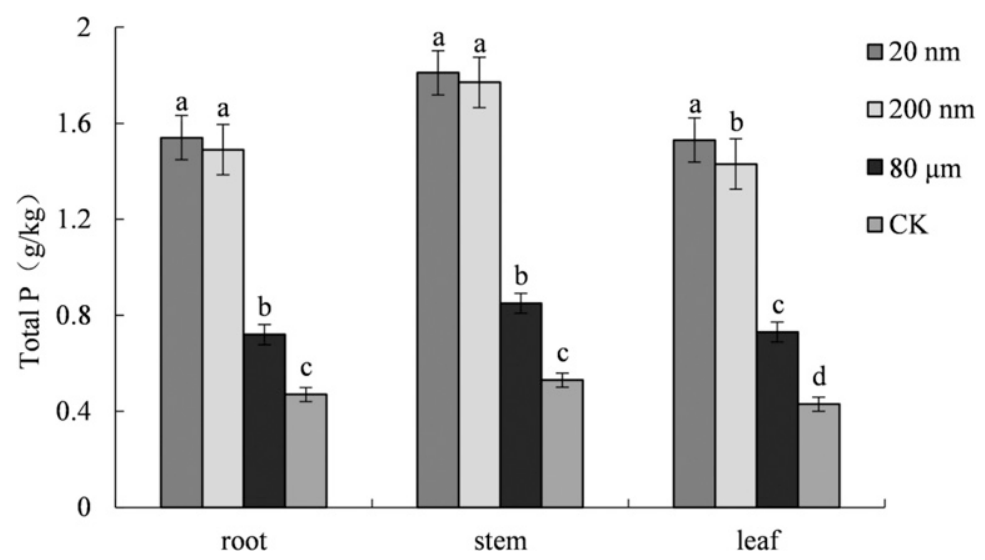

Fig. 7. Effects of different treatments on total phosphorus $(\mathrm{P})$ contents in the roots, stems, and leaves of the $C$. oleifera seedlings. Different letters in each column indicate significant differences at the $5 \%$ level according to Duncan's test.

main sorbents for $\mathrm{P}$ in acidic soil are iron $(\mathrm{Fe})$ and aluminum $(\mathrm{Al})$ oxides (Missong et al., 2016; Ilg et al., 2008). According to the soil elemental composition, the tested red acidic soil contained $25.79 \mathrm{~g} / \mathrm{kg} \mathrm{Al}$ and $52.40 \mathrm{~g} / \mathrm{kg}$ $\mathrm{Fe}$, and their contents were significantly higher than those of the other soil elements. Secondary phosphate minerals, which are relatively immobile and sparingly soluble, are formed by the complexation of n-HAP with high levels of $\mathrm{Al}^{3+}$ and $\mathrm{Fe}^{3+}$ cations (Zhao et al., 2006). This also partially explains the retention of some HAP in the soil. Conversely, one study found that the contents of available $\mathrm{P}$ in the $200-\mathrm{nm}$ and $80-\mu \mathrm{m}$ layers after elution by deionized water were similar to the contents before elution because of the large particle sizes and soil filtration effects (Liu and Lal, 2014). However, the total and available $P$
C. oleifera, thus significantly affecting the uptake of the contents of nitrogen and potassium (Yuan 2013). Research has found that the optimum $\mathrm{P}$ application for 5-year-old C. oleifera seedlings is $3.93 \mathrm{~g} / \mathrm{kg}$ per month (Luo et al., 2016), and the growth of 1-yearold $C$. oleifera seedlings with a $\mathrm{P}$ content of $100 \mathrm{mg} / \mathrm{kg}$ was better than the growth with $50 \mathrm{mg} / \mathrm{kg}$ P (Qu et al., 2018). By combining sorption properties with a strong and large surface area, nanofertilizers have the potential advantages of sustained and slow release (Bindraban et al., 2015); therefore, n-HAP may be used as a more effective substitute for traditional phosphate fertilizers. With the 20$\mathrm{nm}$ and $200-\mathrm{nm}$ HAP particle treatments, the growth of the seedlings was significantly promoted because of the increased content of available $\mathrm{P}$ in the rhizosphere soil. As the rate of dissolution increases with decreasing particle size, migration and dissolution abilities improve (Borm et al., 2006). The low particle size also assists with uptake by plant roots. The level of available $\mathrm{P}$ in the rhizosphere soil was significantly higher than that in the nonrhizosphere soil because plants promote the transformation of HAP to available $\mathrm{P}$ by secreting small-molecule organic acids and adjusting the $\mathrm{pH}$ in the rhizosphere (Liao et al., 2006). The HAP particles were thus transported to the roots through the mass produced by plant transpiration. The results showed that the effects of $80-\mu$ m HAP on the seedlings were not as apparent as those of the 20-nm n-HAP and 200-nm HAP treatments. We found that most of the $80-\mu \mathrm{m}$ HAP became trapped in the shallow soil and could not be effectively absorbed and used by plants, which may be related to its slow dissolution (Borm et al., 2006). Previous studies also indicated that reducing the particle size of slightly soluble $\mathrm{P}$ could improve agronomic efficiency (Alston and Chin, 1974) because increasing the dissolution rates can promote particle-to-root contact (Khasawneh and Doll, 1979; Watkinson 1994). There were no significant differences in the physiological indexes, total $\mathrm{P}$ content, and soil available $P$ content between plants treated with HAP sizes of $20 \mathrm{~nm}$ and $200 \mathrm{~nm}$. This showed that the practical application of 20$\mathrm{nm}$ n-HAP is in line with that of $200-\mathrm{nm}$ HAP. However, the results of the column experiment indicated that n-HAP of $20 \mathrm{~nm}$ migrated more easily in the red soil than HAP of $200 \mathrm{~nm}$. We believe that the aggregation propensity of $n$-HAP has a significant effect on the dissolution rate of the particles, which affects the P bioavailability of HAP in C. oleifera. This is consistent with the earlier hypothesis of Montalvo et al. (2015).

\section{Conclusions}

The present study found that 20-nm nHAP had better mobility than the $200-\mathrm{nm}$ and $80-\mu \mathrm{m}$ HAP. This was likely attributable to its smaller particle size. The $20-\mathrm{nm}$ and 200-nm HAP treatments had similar effects on the growth of $C$. oleifera seedlings, but the higher adsorption of the $200 \mathrm{~nm}$ HAP 


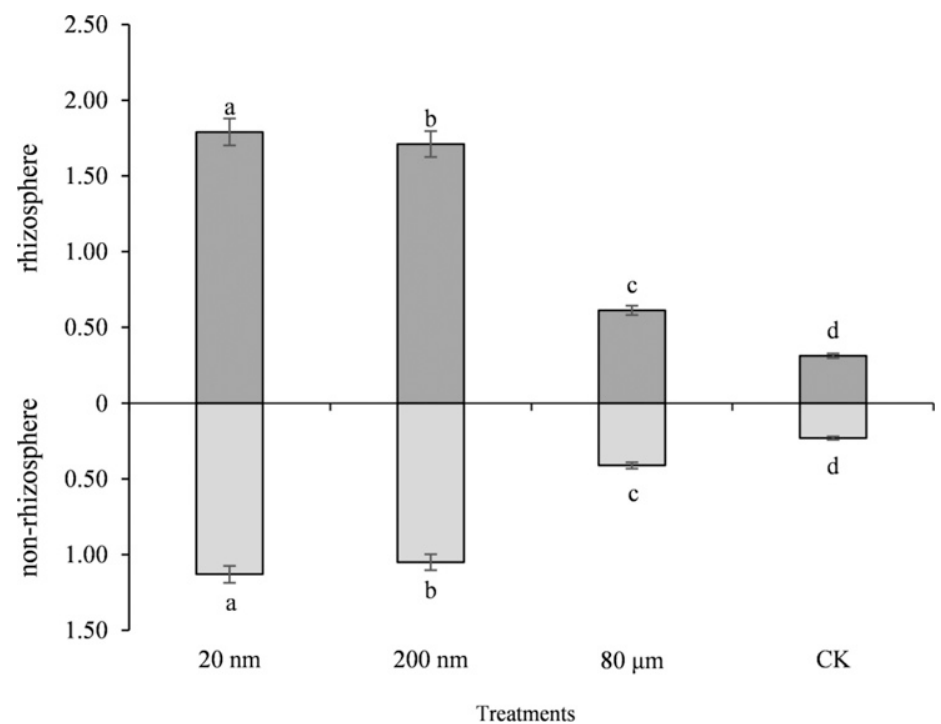

Fig. 8. Effects of different treatments on available phosphorus (P) contents in the rhizosphere and nonrhizosphere soil. Different letters in each column indicate significant differences at the $5 \%$ level according to Duncan's test.

indicated that it exhibited more efficient $\mathrm{P}$ fertilizer utilization. This research may help alleviate $\mathrm{P}$ deficiency in red acidic soil and provide a basis for the application of HAP as $\mathrm{P}$ fertilizer in C. oleifera orchards.

\section{Literature Cited}

Alston, A.M. and K.W. Chin. 1974. Response of subterranean clover to rock phosphates as affected by particle size and depth of mixing in the soil. Austral. J. Expt. Agr. 14(70):649-655, doi: 10.1071/EA9740649.

Bindraban, P.S., C. Dimkpa, L. Nagarajan, A. Roy, and R. Rabbinge. 2015. Revisiting fertilisers and fertilisation strategies for improved nutrient uptake by plants. Biol. Fertil. Soils 51:897-911, doi: 10.1007/s00374-015-1039-7.

Borm, P., F. Klaessig, T. Landry, B. Moudgil, J. Pauluhn, K. Thomas, R. Trottier, and S. Wood. 2006. Research strategies for safety evaluation of nanomaterials, Part V: Role of dissolution in biological fate and effects of nanoscale particles. Toxicol. Sci. 90(1):23-32, doi: 10.1093/ toxsci $/ \mathrm{kfj} 084$.

Chen, A. and Y. Arai. 2020. Current uncertainties in assessing the colloidal phosphorus loss from soil. Adv. Agron. 163: doi: 10.1016/bs.agron.2020. 05.002 .

Chen, Y., S. Peng, X. Wang, X. Yang, J. He, and D. Wang. 2007. Study of high yield cultivation technologies of oil-tea camellia (Camellia oleifera)Formulate fertilization. For. Res. 20:650-655, doi: 10.3321/j.issn:1001-1498.2007.05.010.

Du, Z., J. Zhou, H. Wang, X. Chen, C. Du, and Q. Wang. 2010. Phosphorus movement and transformation in fertilizer microsites in red soil as affected by nitrogen and potassium application. Acta Pedologica Sinica 47(03):497-502, doi: 10.11766/trxb200812230315.

Ghanati, F., A. Morita, and H. Yokota. 2005. Effects of aluminum on the growth of tea plant and activation of antioxidant system. Plant Soil 276(1-2): doi: 10.1007/s11104-005-3697-y.

Gremion, F., A. Chatzinotas, and H. Harms. 2003. Comparative 16S rDNA and 16S rRNA sequence analysis indicates that Actinobacteria might be a dominant part of the metabolically active bacteria in heavy metal-contaminated bulk and rhizosphere soil. Environ. Microbiol. 5(10): doi: 10.1046/j.1462-2920.2003.00484.x.

He, G., J. Zhang, X. Hu, and J. Wu. 2011. Effect of aluminum toxicity and phosphorus deficiency on the growth and photosynthesis of oil tea (Camellia oleifera Abel.) seedlings in acidic red soils. Acta Physiol. Plant. 33(4):1285-1292, doi: 10.1007/s11738-010-0659-7.

Ilg, K., P. Dominik, M. Kaupenjohann, and J. Siemens. 2008. Phosphorus-induced mobilization of colloids: Model systems and soils. Eur. J. Soil Sci. 59(2):233-246, doi: 10.1111/j.1365-2389. 2007.00982.x.

Jiang, H., J. Guo, X. Liu, S. Qiao, X. Zhang, K. Guo, J. Zhang, and J. Yang. 2017. Effects of combined application of nitrogen from different source on nitrogen utilization of spring maize and sustainability of soil fertility in Northeast China. J. Plant Nutr. Fert. 23(04):933-941, doi: 10.11674/zwyf.16249.

Jiao, W., W. Chen, A. Chang, and A. Page. 2012. Environmental risks of trace elements associated with long-term phosphate fertilizers applications: A review. Environ. Pollut. 168:44-53, doi: 10.1016/j.envpol.2012.03.052.

Jin, X., X. Zeng, C. Qi, L. Yin, and Y. Deng. 2018. Influences of phosphorus application level on maize arbuscular mycorrhizal colonization and hyphal acquisition to heterogeneous phosphorus supply. J. Plant Nutr. Fert. 24(01):163-169, doi:

Khasawneh, F.E. and E.C. Doll. 1979. The use of phosphate rock for direct application to soils. Adv. Agron. 30(C):159-206, doi: 10.1016/ S0065-2113(08)60706-3.

Koutsopoulos, S. 2002. Synthesis and characterization of hydroxyapatite crystals: A review study on the analytical methods. J. Biomed. Mater. Res. 62(4):600-612, doi: 10.1002/jbm.10280.

Li, D., J. Zhang, Y. He, Y. Qin, Y. Wei, P. Liu, L. Zhang, J. Wang, Q. Li, S. Fan, and K. Jiang. 2017. Scanning electron microscopy imaging of single-walled carbon nanotubes on substrates. Nano Res. 10(5):1804-1818, doi: 10.1007/s12274-017-1505-7.

Li, H., Z. Yang, M. Dai, X. Diao, S. Dai, T. Fang, and X. Dong. 2020. Input of Cd from agriculture phosphate fertilizer application in China 10.11674/zwyf.17239. during 2006-2016. Sci. Total Environ. 2-3: doi: 10.1016/j.scitotenv.2019.134149.

Liao, H., H. Wan, J. Shaff, X. Wang, X. Yan, and L. Kochian. 2006. Phosphorus and aluminum interactions in soybean in relation to aluminum tolerance. exudation of specific organic acids from different regions of the intact root system. Plant Physiol. 141(2):674-684, doi: 10.1104/ PP.105.076497.

Liu, R. and R. Lal. 2014. Synthetic apatite nanoparticles as a phosphorus fertilizer for soybean (Glycine max). Sci. Rep. 4:5686, doi: 10.1038/ srep05686.

Luo, H., C. Zhu, L. Zhang, D. Hu, S. Tu, X. Guo, and D. Niu. 2016. Effects of phosphorus fertilization levels on vegetative growth in Camellia oleifera. Non-wood For. Res. 34(04):52-56, doi: 10.14067/j.cnki.1003-8981.2016.04.009.

Lv J., D. Xu, and F. Li, 2012. Effects of different environmental factors on the transportation of black soil colloid in saturated porous media. Res. Environ. Sci. 25(08):875-881, doi: CNKI: SUN:HJKX.0.2012-08-007.

Masayasu, N., K. Takashiet, and A. Masakazual. 2000. Correction methods of $\gamma$ - ray self-absorption in bulk sample. Radioisotopes 49(4):189, doi: 10.3769/radioisotopes.49.189.

Missong, A., R. Bol, S. Willbold, J. Siemens, and E. Klumpp. 2016. Phosphorus forms in forest soil colloids as revealed by liquid-state 31P-NMR. J. Plant Nutr. Soil Sci. 179(2): doi: 10.1002/ jpln.201500119.

Montalvo, D., M. McLaughlin, and F. Degryse. 2015. Efficacy of hydroxyapatite nanoparticles as a $P$ fertilizer in andisols and oxisols. Soil Sci. Soc. Amer. J. 60(5):14, doi: 10.2136/sssaj2014. 09.0373.

Powers, K., S. Brown, V. Krishna, S. Wasdo, B. Moudgil, and S. Roberts. 2006. Research strategies for safety evaluation of nanomaterials, Part VI: Characterization of nanoscale particles for toxicological evaluation. Toxicol. Sci. 90:296-303, doi: 10.1093/toxsci/kfj099.

Qu X., H. Wang, X. Deng, Y. Yu, S. Dai, and J Yuan. 2018. Effects of phosphorus and aluminum interaction on seedling growth of Camellia vietnamensis Huang. and phosphorus and aluminum contents in it. J. Southern Agr. 49(03):508-515, doi: CNKI:SUN:GXNY.0.2018-03-015.

Qu, X., J. Zhou, J. Masabni, and Y. Jun. 2020. Phosphorus relieves aluminum toxicity in oil tea seedlings by regulating the metabolic profiling in the roots. Plant Physiol. Biochem. 152:12-22, doi: 10.1016/j.plaphy.2020.04.030.

Rai, M., C. Ribeiro, L. Mattoso, and N. Duran. 2015. Nanotechnologies in food and agriculture. Springer, Cham, Switzerland.

Ryan, I. 2002. Efficient use of phosphate fertilizers for sustainable crop production in WANA. Phosphate Newsletter. 2-5.

Saleem, H. and S. Zaidi. 2020. Recent developments in the application of nanomaterials in agroecosystems. Nanomaterials 10(12):2411, doi: 10.3390/nano10122411.

Shi, R., S. Bao, and H. Qin. 1996. Soil agro-chemistrical analysis. Agriculture Press, Beijing.

Szameitat, A., A. Sharma, F. Minutello, A. Pinna M. Er-Rafik, T. Hansen, and D. Persson. 2021. Unravelling the interactions between nanohydroxyapatite and the roots of phosphorus deficient barley plants. Environ. Sci. Nano 8(2), doi: 10.1039/d0en00974a.

Ukwattage, N., Y. Li, Y. Gan, T. Li, and R. Gamage. 2020. Effect of biochar and coal fly ash soil amendments on the leaching loss of phosphorus in subtropical sandy ultisols. Water Air Soil Pollut. 231(2), doi: 10.1007/ s11270-020-4393-5. 
Wang, D., Y. Xie, D. Jaisi, and Y. Jin. 2016. Effects of low-molecular-weight organic acids on the dissolution of hydroxyapatite nanoparticles in batch and column experiments: a perspective from phosphate oxygen isotope fractionation. Environ. Sci. Nano 3(4), doi: 10.1039/c6en00085a.

Watanabe, Y., H. Yamada, T. Ikoma, J. Tanaka, G. Stevens, and Y. Komatsu. 2013. Preparation of a zeolite $\mathrm{NaP} 1 /$ hydroxyapatite nanocomposite and study of its behavior as inorganic fertilizer. J. Chem. Eng. Data 89(7):963-968, doi: $10.1002 /$ jctb. 4185 .

Watkinson, J.H. 1994. Dissolution rate of phosphate rock particles having a wide range of sizes. Soil Res. 32:1009-1014, doi: 10.1071/SR9941009.

Yang, C., X. Liu, Z. Chen, Y. Lin, and S. Wang. 2016. Comparison of oil content and fatty acid profile of ten new camellia oleifera cultivars. J. Lipids, doi: $10.1155 / 2016 / 3982486$.

Yuan, J. 2013. Study on adaptive mechanism of camellia oleifera to low-phosphorous environment. Dissertation, Beijing Forestry University.

Yuan, J., L. Huang, N. Zhou, H. Wang, and G. Niu. 2017. fractionation of inorganic phosphorus and aluminum in red acidic soil and the growth of camellia oleifera. HortScience 1293-1297: doi: 10.21273/hortsci12189-17.

Yuan, J., X. Tan, S. Ye, N. Zhou, and B. Shi. 2013. The organic acids in root exudates of oiltea and its role in mobilization of sparingly soluble phosphate in red soil. J. Chem. Pharm. Res. 5(11):572-577.

Zang, L. 2011. Colloidal phosphorus transport and potential loss in paddy soil with different degree of phosphorus saturation. Dissertation, Zhejiang University.

Zhang K., and M. Wang. 2014. Effect of ionic strength and fulvic acid on the transport of $\mathrm{TiO}_{2}$ nanoparticles in soil. Guangzhou Chem. Ind. (23):110-111, doi: CNKI:SUN:GZHA.0. 2014-23-044.

Zhao, K., X. Zheng, C. Chen, and J. Shang. 2018. Effects of heterogeneity on migration of tracer and montmorillonite colloid in saturated porous medium. J. Soil Water Conserv. 32(3):140-145, doi: 10.13870/j.cnki.stbcxb.2018.03.022.

Zhao, Q., D. Zeng, Z. Yu, B. Deng, and Z. Fang. 2006. Rhizosphere effects of Pinus sylvestris var. mongolica on soil phosphorus transformation. Chinese J. Appl. Ecol. 17(8):1377-1381, doi: $10.1360 / \mathrm{yc}-006-1280$ 

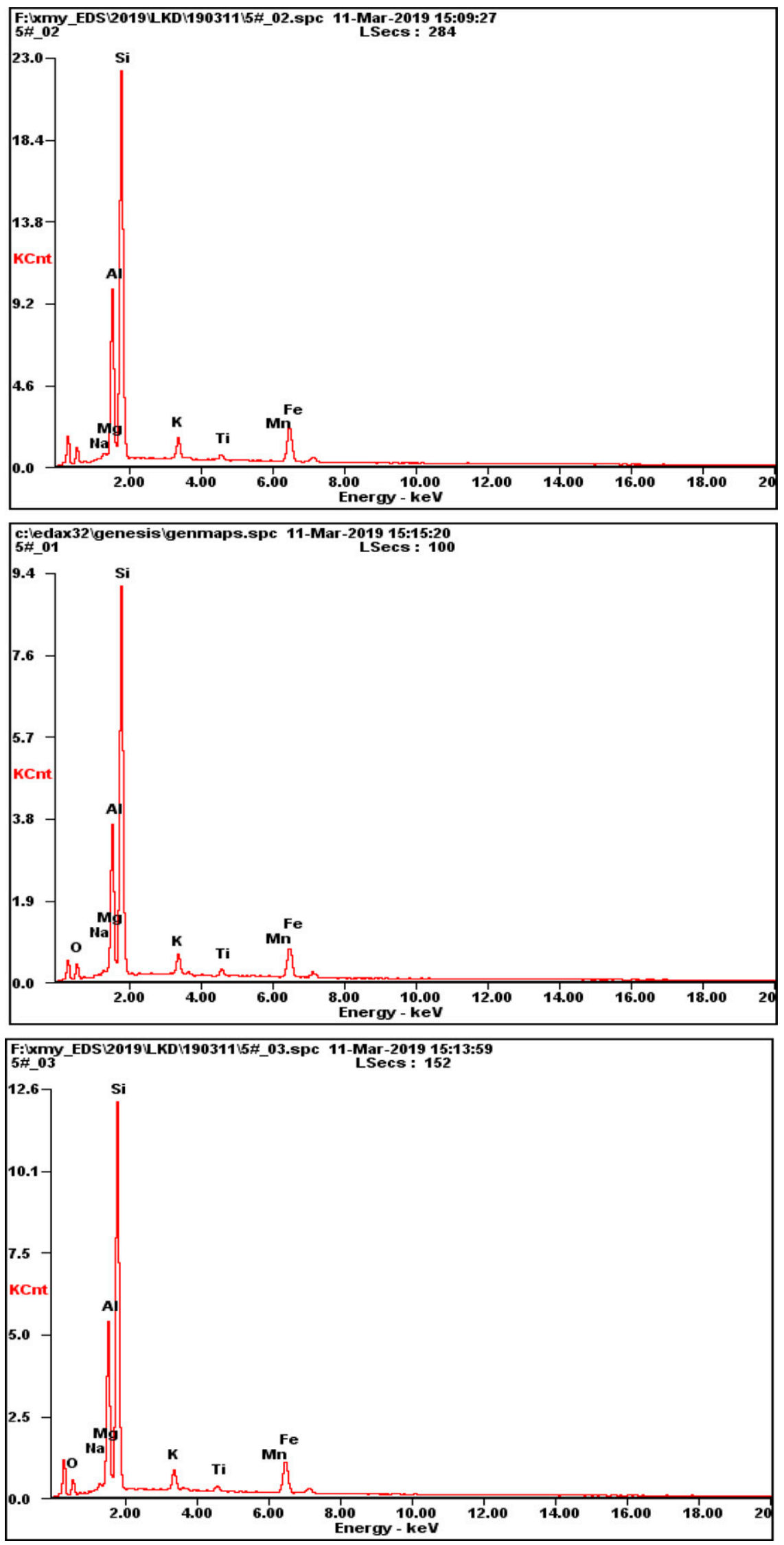

Supplemental Fig. 1. Soil energy spectrum (three replications). 


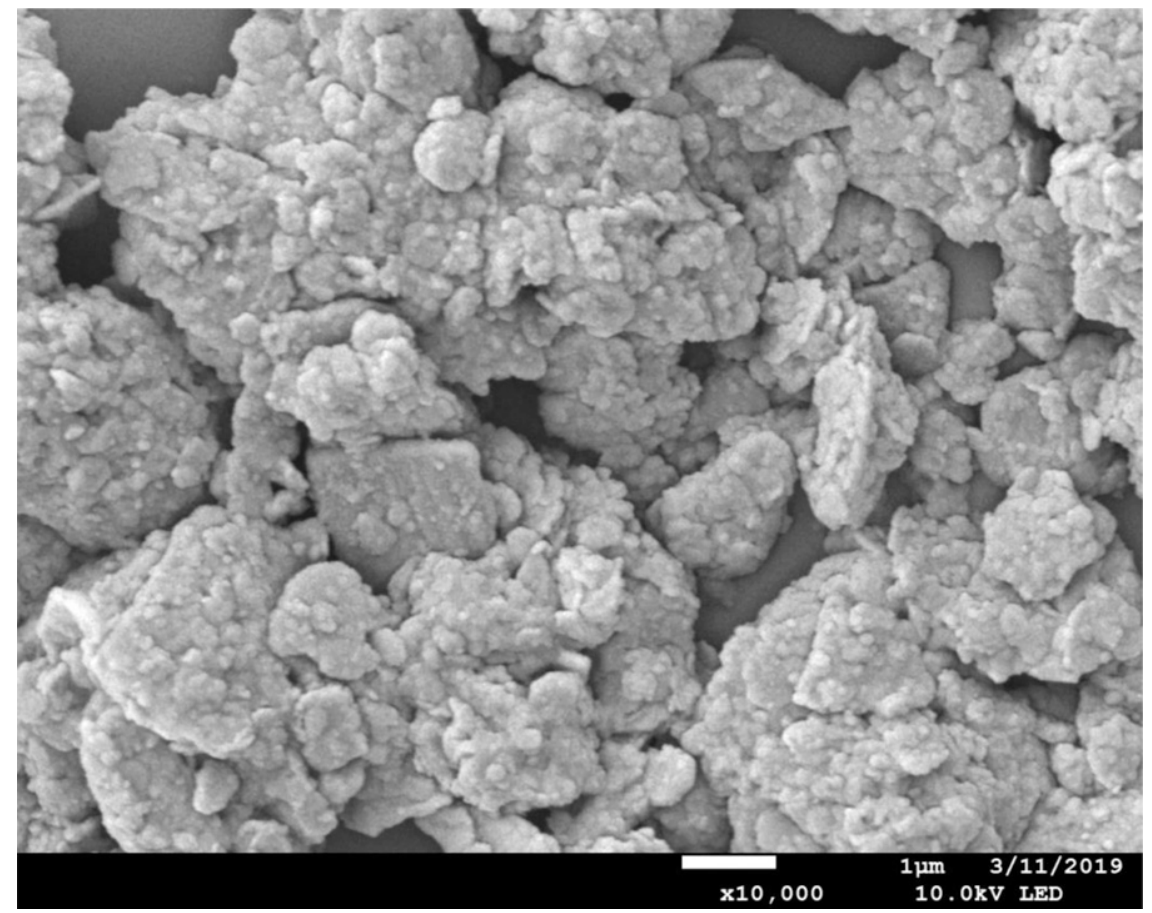

Supplemental Fig. 2. Scanning electron microscopy images of soil.

Supplemental Table 1. Proportion of chemical compounds in the soil energy spectrum (three replications).

\begin{tabular}{lcc}
\hline Element & Wt\% & At\% \\
\hline NaK & 00.05 & 00.07 \\
MgK & 00.80 & 01.03 \\
AlK & 19.90 & 23.09 \\
SiK & 54.57 & 60.82 \\
KK & 04.13 & 03.30 \\
TiK & 01.70 & 01.11 \\
MnK & 00.41 & 00.23 \\
FeK & 18.44 & 10.34 \\
Matrix & Correction & ZAF \\
\hline Element & $\mathbf{W t} \%$ & $\mathbf{A t} \%$ \\
\hline NaK & 00.00 & 00.00 \\
MgK & 00.56 & 00.72 \\
AlK & 18.88 & 21.86 \\
SiK & 56.33 & 62.67 \\
KK & 04.26 & 03.40 \\
TiK & 01.81 & 01.18 \\
MnK & 00.57 & 00.33 \\
FeK & 17.60 & 09.84 \\
Matrix & Correction & ZAF \\
\hline Element & Wt\% & At\% \\
\hline NaK & 00.00 & 00.00 \\
MgK & 00.79 & 01.01 \\
AlK & 19.67 & 22.70 \\
SiK & 55.86 & 61.91 \\
KK & 04.28 & 03.41 \\
TiK & 01.70 & 01.10 \\
MnK & 00.40 & 00.23 \\
FeK & 17.30 & 09.64 \\
Matrix & Correction & ZAF \\
\hline & &
\end{tabular}

